\title{
Article
}

\section{Elementary School Students' Epistemic Perspective and Learning Strategies in History}

Ioannou, Kalia and Iordanou, Kalypso

Available at http://clok.uclan.ac.uk/26384/

Ioannou, Kalia and Iordanou, Kalypso ORCID: 0000-0001-5930-9393 (2020)

Elementary School Students' Epistemic Perspective and Learning Strategies in History. Learning: Research and Practice, 6 (2). pp. 150-166. ISSN 2373-5082

It is advisable to refer to the publisher's version if you intend to cite from the work. http://dx.doi.org/10.1080/23735082.2019.1591492

For more information about UCLan's research in this area go to http://www.uclan.ac.uk/researchgroups/ and search for < name of research Group>.

For information about Research generally at UCLan please go to http://www.uclan.ac.uk/research/

All outputs in CLoK are protected by Intellectual Property Rights law, including Copyright law. Copyright, IPR and Moral Rights for the works on this site are retained by the individual authors and/or other copyright owners. Terms and conditions for use of this material are defined in the policies page. 


\title{
Elementary School Students' Epistemic Perspective and Learning Strategies in History
}

\author{
Kalia Ioannou ${ }^{\mathrm{a}}$ and Kalypso Iordanou ${ }^{\mathrm{b} *}$ \\ ${ }^{a}$ Neapolis University, Pafos, Cyprus

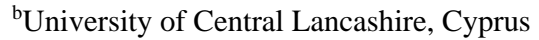

The present study explores possible relations between students' epistemic perspective, learning strategies and text comprehension. In Study 1, seventy-nine sixth graders completed paper-and-pencil instruments to measure their epistemic perspective and learning strategies. Students' epistemic perspective was assessed using the Livian problem (Kuhn, Iordanou, Pease, \& Wirkala, 2008), which presented two contradicting accounts about the fictitious fifth Livian war and asked students questions regarding the certainty of their knowledge. Students were epistemically profiled as Absolutists, Multiplists and Evaluativists in their approaches to knowing. Students' learning strategies were assessed through the Motivated Strategies for Learning Questionnaire - MSLQ (Pintrich \& De Groot, 1990). In Study 2, twenty of the students who participated in Study 1 were individually interviewed to measure their learning strategies, where they were asked to read a text about Columbus' uncovering of the New World. Results revealed that students who were profiled as Evaluativists showed greater self-efficacy, intrinsic value, use of cognitive strategies and self-regulation. In addition, students who were profiled as Evaluativists engaged in more effective learning strategies and exhibited better text comprehension compared to students who were profiled as Absolutists. In particular, students who exhibited an Evaluativist epistemic perspective engaged in the strategies of understanding vocabulary, summarizing and underlining, while students who exhibited an Absolutist epistemic perspective engaged more in repeating information and quick reading. Our findings show that a mature epistemic perspective is associated with effective usage of learning strategies and text comprehension.

Keywords: epistemic perspective; learning strategies; history; young adolescents; thinkalouds 


\section{Background}

The present study explores possible relations between students' epistemic perspective (EP), defined as students' "knowledge, beliefs, ideas, and theories regarding the nature of knowledge and knowing" (Barzilai \& Zohar, 2014, p. 20), and learning strategies in the context of history. Previous studies showed that EP is associated with academic performance (Hofer, 2000; Schommer, 2004; Schommer \& Easter, 2006) and learning outcomes (Schommer, 2004). However, previous work examined relations between general academic performance and EP. The present work attempted to unpack this relation by examining possible relations between learning strategies in particular and EP in history.

\section{Epistemic Perspective}

The word epistemic refers specifically to facets of knowledge and knowing. Epistemic cognition is a broad term which "concerns how people acquire, understand, justify, change, and use knowledge in formal and informal contexts” (p. 2, Greene, Sandoval, \& Bråten. 2016). Piaget (1950) coined the term genetic epistemology to describe his theory of intellectual development, initiating thus the interest of developmental psychologists in the intersection of philosophy and psychology. These interests were a very important step in the growing reaction to the dominance of behaviourism. Perry's (1970) study, which aimed to understand the way that students interpreted pluralistic educational experiences, was the first study to reveal the central role of EP in learning. Since then, a flourishing body of research has examined EP focusing mainly on the following general issues: (a) refining and extending Perry's developmental sequence; (b) developing more simplified measurement tools for assessing such development; (c) exploring gender-related patterns in knowing; (d) examining how epistemic awareness is a part of thinking and reasoning processes; (e) identifying dimensions of EP; and, most recently, (f) assessing how these beliefs link to other cognitive and motivational processes (Greene, Sandoval, \& Bråten, 2016). 
However, in this body of research there is very little agreement on the construct under study, the dimensions it encompasses, whether EP is domain specific or how such perspective might connect to disciplinary beliefs, and what the linkages might be to other constructs in cognition and motivation. In addition, there have been no attempts to conceptually integrate the early Piagetian-framed developmental work on EP to newer cognitive approaches such as theory of mind or conceptual change (Hofer \& Pintrich, 1997; Iordanou, 2016a). There are two basic models in the area of epistemic cognition the multidimensional model (Schommer, 1990) and the developmental model (Kuhn, 2001). The multidimensional model suggests that epistemological ideas are a system of beliefs that may be more or less independent rather than reflecting a coherent developmental structure (Ryan, 1984a, 1984b; Schommer, 1990, 1994b). According to the multidimensional model, EP is the result of five factors (certain knowledge, simple knowledge, quick learning, omniscient authority and innate ability). Each of these factors is viewed as a continuum (Schommer, 1990). On the other hand, the developmental approach proposes that epistemic cognition develops throughout the life span and this development constitutes a dimension of cognitive development more generally (Iordanou, 2016). According to the developmental model, the development of EP proceeds through three levels. At the first level, the Absolutist level, knowledge is viewed as an objective entity, located in the external world and knowable with certainty. At the second level, the Multiplist level, the source of knowledge relocates from the known object to the knowing subject, hence individuals become aware of the uncertain, subjective nature of knowing. This awareness overpowers and obliterates any objective standard that could serve as a basis for comparison or evaluation of conflicting claims. Because claims are subjective opinions freely chosen by their holders and everyone has a right to their opinion, all opinions are considered as equally right. At the third level, the Evaluativist level, the objective dimension of knowledge is 
reintegrated with the subjective dimension of knowledge, by acknowledging uncertainty without forsaking evaluation (Hofer \& Pintrich, 1997).

Epistemic perspective progresses developmentally, but substantial variation remains among adults, with some adults not achieving an understanding of the role of evidence and justification in argument (Iordanou, 2016a). Intervention programs might support the development of EP (Alexander, 2016; Barzilai \& Chinn, 2017; Greene, 2016). For example, engagement in argumentation activities (Iordanou, 2016b; Iordanou \& Constantinou, 2014; 2015), or constructivist teaching practices (Muis \& Duffy, 2013) appear a promising condition for supporting the development of EP.

In the present study, extending previous work which revealed that there is a relation between epistemic perspective, when the developmental model was employed, and strategies used both during reading a text (Iordanou, Muis, Kendeou, 2018) and writing argumentive essays (Iordanou, Kendenou, Baker, 2016), we examine relations between one's developmental level in epistemic cognition and strategies employed during learning. We adopt the developmental model of epistemic cognition because we are particularly interested in examining if there is a relation between one's developmental level in epistemic cognition and learning, particularly the learning strategies that s/he employs. We discuss epistemic perspective and learning below.

\section{Epistemic Perspective and Learning}

Some researchers proposed that students' EP has direct and indirect effect on learning (Schommer-Aikins, 2002; Topcu \& Yilmaz-Tuzun, 2008). There are two theoretical models which propose that there is a relationship between EP and learning strategies; one has been proposed by Muis (2007) and the other by Kuhn (2001). By incorporating EP within the selfregulated learning framework, Muis (2007) proposed four phases of self-regulated learning and four areas for regulation. The four phases include task definition, planning and goal setting, enactment and evaluation. The four areas for regulation include cognition (knowledge 
activation, knowledge of strategies), motivation and affect (achievement goals, self-efficacy), behaviour (time, effort), and context (resources, social context). Muis (2007) supported that these four areas may be regulated during each of the four phases of self-regulated learning. Based on this model, she proposed that EP is one component of the cognitive and affective conditions of a task. She further argued that during task definition, when schemas or nodes for domain knowledge or knowledge of a task are activated, schemas for beliefs about knowledge and knowing are also activated (Muis, 2007). The activation of EP schemas provides the opportunity for those beliefs to exert an influence over other facets of self-regulated learning.

According to Kuhn's model (2001), one's EP determine whether and how one engages in learning and critical thinking. At the Absolutist level, an individual who views knowledge as an objective entity and believes that there is a single truth, in case of encountering opposing theories s/he will try to find out which one is the correct one, usually by asking an expert or someone who had first-hand experience with the matter at hand. At the Multiplist level, an individual who views knowledge as totally subjective, when encountering opposing views about an issue $\mathrm{h} / \mathrm{she}$ will not be motivated to engage in critical thinking to find which view is better. At the Evaluativist level, an individual who views knowledge as the reintegration of the objective and subjective dimensions of knowing, in case of encountering opposing views about an issue, s/he will engage in critical thinking to find out which position has more merit depending on which one is better supported by argument and evidence (Kuhn, 2001). Besides the theoretical models, there is empirical evidence showing that there is a relationship between EP and learning, focusing on learning strategies or text comprehension, the outcome of learning, which we discuss below.

Epistemic Perspective and Learning Strategies. There are some empirical evidence showing a relation between epistemic perspective and learning strategies. For example, Franco and Muis (2009), examined 201 undergraduate students in the context of an educational psychology 
course, using the Discipline-Focused Epistemological Beliefs Questionnaire (DFEBQ), the Achievement goals Questionnaire (AGQ) and the Motivated Strategies for Learning Questionnaire (MSLQ). They found that participants' EP directly influenced the types of achievement goals that students set for their tasks in that course. Students' achievement goals, in turn, influenced their learning strategies, EP and ultimately their performance (Franco \& Muis, 2009). Greene et al. (2014) reported a relationship between EP and self-regulated learning. In their study, they examined the way that self-regulated learning and EP interact and relate to learning in digital environments. They used a think-aloud protocol analysis, to investigate the relations among self-regulated learning, EP, and learning gains with 20 college students who studied vitamins on the internet. Their findings showed that a sophisticated view of knowledge, as well as a frequent use of elaborative learning strategies were positive predictors of learning.

Epistemic Perspective and Text Comprehension. Besides the relation between EP and learning strategies, a relation has been reported between EP and text comprehension (Bråten \& Strøms $\varnothing$, 2011; Bråten, Strømsø, \& Samuelstuen, 2008; Strømsø, Bråten, \& Samuelstuen, 2007). An adequate psychological theory of text comprehension should be able to account for the generation of inferences when readers construct a situation model of what a text is about (Graesser, Singer, \& Trabasso, 1994). Bråten, Britt, Strømsø, and Rouet (2011) proposed a model that incorporates EP into a theoretical framework so as to explain multiple-text comprehension. In this framework, EP was related to multiple-text comprehension. For example, EP was considered to facilitate multiple-text comprehension because it might promote intertextual strategic processing and help readers organize their mental representations as integrated argument schemas. Strøms $\varnothing$, Braten, and Samuelstuen (2007) provided some empirical evidence of the relation between EP and text comprehension. Investigating the dimensions of topic-specific EP as predictors of multiple text understanding about climate 
change by examining undergraduate students, Strøms $\varnothing$ et al. (2007) found that the belief that knowledge consists of highly interrelated concepts positively predicted scores on reading tasks. Their results indicated that readers with different EP exhibited different comprehension of multiple texts about the same topic. Similar findings were reported by Bråten, Strømsø, and Samuelstuen (2008) who found that when undergraduate university students tried to understand multiple texts about a relatively unfamiliar, complex topic, those who believed that knowledge was theoretical and complex and relied on experts, were at a particular advantage with respect to both intratextual and intertextual deep-level comprehension. Consistent with these findings, Bråten, Britt, Strøms $\varnothing$ and Rouet (2011) and Iordanou, Muis and Kendeou (2018) found that readers who believed that knowledge claims need to be justified through the use of critical thinking, rules of inquiry, and the evaluation and integration of various information sources engaged in more metacognitive thinking when encountering opposing claims located in different texts or in the same text.

Previous research focusing on adults samples showed that there is a relationship between EP and text comprehension. However, the relationship between EP and text comprehension in adolescents has been examined only in the context of the domain of science. The possible relationship between EP and text comprehension in adolescents in the domain of history has not been examined yet. Below we discuss research about EP and learning in the domain of history.

\section{Epistemic Perspective and Learning in History}

Most of the studies which examined the relation between EP and learning have focused on science learning. There are limited studies in the domain of history, which focused on examining epistemic beliefs (Kuhn, Iordanou, Pease, \& Wirkala, 2008; Maggioni, 2010; Maggioni, Alexander, \& VanSledrigh, 2004; O’Neill, Sheryl Guloy \& Özlem Sensoy, 2014). For example, Kuhn, Iordanou, Pease and Wirkala (2008) examined sixth graders' and teachers' epistemic beliefs employing a scenario based instrument, the Livia problem. Kuhn et al. (2008) 
found that only a small percentage, about a quarter, of both sixth graders and teachers held mature, evaluativist, epistemic beliefs in history. Similar results were reported by Maggioni (2010) who examined high school students' and teachers' epistemic beliefs in history using structured interviews collected while participants responded to statements of the Likert-scale Beliefs about History Questionnaire (Maggioni, Alexander, \& VanSledrigh, 2004). The results showed that statements acknowledging the interpretive role of the historian relied on specific disciplinary criteria, which reflect mature epistemic perspective, were rare in participants' responses.

As it is evident from the review of the literature in the history domain above, the limited research thus far in this domain examined learners' and teachers' EP. However, our knowledge about the students' learning processes in the history domain is very limited (VanSledrigh, Burkholdt, \& Montgomery, 2018). Given the limited research in the domain of history about learning, the findings of previous research showing that students do not hold mature epistemic beliefs in history, and the alarming findings that students tend to memorize historical facts instead of engaging in critical thinking when they study history (Dillon, 2011) point to the need for further research in the domain of history, examining learning in history and the possible relation between EP and learning in history. The necessity to gain a better understanding of learning history, particularly during the elementary school which is the first fundamental level that formal history teaching begins, appears imperative given the important role of history for developing informed citizens for democratic societies (Significance of history for the educated citizen, 2018).

The present study aims to address this research gap, namely examining possible relations between students EP and learning processes in the domain of history.

\section{The Present Study}


The present study contributes to the current literature by examining possible relations between elementary students' EP and learning, focusing in particular on the relation between $\mathrm{EP}$, learning strategies and text comprehension, in the context of history. The novelty of the present study is that, unlike previous work which focused on adults and examined EP and learning in the domains of science (Conley, Pintrich, Vekiri \& Harrison, 2004), the present study examines the relation between EP and learning strategies using elementary school students in the domain of history, which is a domain that has not been investigated yet. We examined this relation in a context which is closer to what students are usually asked to do in the context of their normal classroom (i.e. read a text and prepare for a test). We believe that using a task which is closer to their everyday activities has the potential to provide us a clearer understanding of the relation between students' EP and the learning strategies they employ in their everyday school life. In addition, the present study examines learning strategies on-line, by employing the think-aloud methodology, which is a more powerful methodology to assess learning strategies than self-report measures (Greene, Robertson, \& Costa, 2011; Pintrich, Wolters, \& Baxter, 2000).

The research questions of the present study are the following: (1) "Do students with different epistemic perspectives employ different learning strategies?" and (2) "Do individuals with different EP who engage in different learning strategies demonstrate significantly different text comprehension?"

To address these questions we employed two studies. In Study 1 seventy-nine sixth graders completed paper-and-pencil instruments to measure their EP and learning strategies as well as to examine a possible relation between the two. Paper-and-pencil instruments were employed in Study 1 which offer the advantage of collecting a large sample. Students' prior knowledge was also assessed since evidence shows that a person's prior knowledge plays a critical role in learning (Hewson, 2007). To gain a better understanding of the learning strategies that students 
employ and to avoid the threads of self-reported questionnaires (Duckworth \& Kern, 2011), we pursued another study (Study 2) where we conducted individual interviews to examine students' learning strategies. In particular, twenty of the students who participated in Study 1 participated in an individual interview, where they were asked to read a text and think-aloud and then to complete a text comprehension questionnaire. Students' EP was assessed using the Livia problem (Kuhn, et al., 2008), which presented two contradicting accounts about a fictitious fifth Livia war and asked students questions regarding the certainty of their knowledge. Students were epistemically profiled as Absolutists, Multiplists and Evaluativists (Kuhn et al., 2000) in their approaches to knowing. Students' learning strategies were assessed through the Motivated Strategies for Learning Questionnaire - MSLQ (Pintrich \& De Groot, 1990) and through individual interviews.

\section{Methods}

\section{Study 1}

Sample

The sample of Study1 included 79 sixth-grade students from four primary schools in Cyprus. Following simple random sampling, 4 primary schools were randomly chosen to take part in the study. There were 44 girls (55.7\%) and 35 boys ( $44.3 \%)$. The mean age of the students was 12 . The sample was relatively homogeneous (middle class) in regard to their socioeconomic status. Participation was anonymous and voluntary.

\section{Instruments}

Learning strategies questionnaire

The MSLQ, a self-report questionnaire that includes 40 items on student motivation, cognitive strategy use, metacognitive strategy use and management of effort, was used to examine students' learning strategies. The MSLQ is a self-report questionnaire that includes 40 items on student motivation, cognitive strategy use, metacognitive strategy use and 
management of effort. Students were instructed to respond to the items on a 5-point Likert scale $(1=$ not at all true of me to $5=$ very true of me) in terms of their behaviour in learning.

\section{Epistemic perspective instrument}

The Livia problem (Kuhn et al., 2008) presented two contradicting accounts about a fictitious fifth Livia war. Participants were asked questions about the certainty of their knowledge. The questions were: "Could both of the historical reports be right? "Can one view be more right than the other?", "Could anyone ever be certain about what happened in the Fifth Livia war?" and "What would help us become more certain?"

\section{Procedure}

Participants were first administrated the MSLQ test. They were instructed to answer all the questions in the questionnaire. Then, participants were given the Livia problem. They were instructed to read the two texts, in a counter-balanced order, and answer the questions that follow. The two tests lasted about 40 minutes and their completion took place in the participants' classroom.

\section{Coding Schemes}

Learning strategies - MSLQ questionnaire

The coding scheme developed by Pintrich and De Groot (1990) was used to code participants' responses in the MSLQ questionnaire. The MSLQ questionnaire included four sub-categories: self-efficacy, intrinsic value, cognitive strategy use and self-regulation. Self-efficacy is a selfappraisal of one's ability to master a task. Intrinsic value concerns the degree to which the student perceives him/herself to be participating in a task for reasons such as challenge, curiosity, and mastery. Cognitive strategy use expresses how often somebody attempts to summarize or paraphrase the material one reads in textbooks, and how often one tries to relate the material to what they already know or has learnt. Finally, self-regulation is about planning, 
monitoring, and regulating one's knowledge. Different scores were calculated for each subcategory.

\section{Epistemic perspective - Livia problem}

Based on their responses to the Livia problem, students were profiled as Absolutists, Multiplists or Evaluativists using the coding scheme developed by Kuhn et al. (2008). In particular, those students who responded that certainty was possible and could be achieved via direct observation or examination of data (e.g. "Talk to anyone who was alive at that time") were coded as Absolutists while those who claimed that certainty was not possible because of the subjectivity of human knowing (e.g. "Anyone has a different view about history") were classified as Multiplists. Finally, those who claimed that certainty was not possible but approachable through investigation and interpretation (e.g. "Trying to find artifacts of the country that will give us clues of what happened") were coded as Evaluativists (Kuhn et al., 2008) (see Table 1 for examples). Since a satisfactory percentage of agreement was achieved between the two coders based on $20 \%$ of the data coded by both of them - inter-rater reliability, Cohen's kappa, was .83 - it was decided for reasons of practicality that one of them would code the rest of the data. This is a common practise in coding this kind of data (Hruschka, Schwart, St. John, PiconeDecaro, Jenkins, \& Carey, 2004).

Table 1

\section{Results and Discussion}

\section{Preliminary Analysis}

Descriptive statistics (means, standard deviations, values of skewness and kurtosis, and maximum scores) for measured variables of MSLQ are displayed in Table 2, which also 
indicates that all score distributions were approximately normal according to KolmogorovSmirnov test and, thus, appropriate for use in parametric statistical analyses.

Table 2

Intercorrelations between the variables of MSLQ are shown in Table 3. It can be seen that all variables correlated positively and statistically significantly between each other.

Table 3

For answering research question one, that is "Do students with different levels of EP employ different learning strategies?", we performed a one-way analysis of variance (ANOVA) on students' scores on the MSLQ questionnaire. We compared the scores of Absolutists, Multiplists and Evaluativists for the four strategies identified in the MSLQ questionnaire. The analysis was significant for all the four strategies identified in the MSLQ questionnaire, selfefficacy, $F(2,72)=18.06, p<0.001$, intrinsic value, $F(2,72)=14.68, p<0.05$, cognitive strategy use $F(2,72)=12.97, p<0.001$ and self-regulation $F(2,72)=14.15, p<0.001$. Post hoc analyses using the Scheffé post hoc criterion for significance indicated that students who were profiled as Evaluativists showed greater self-efficacy $(\boldsymbol{p}=\mathbf{0 . 0 3}$ to 0.02$)$, intrinsic value $(p=0.04$ to 0.01$)$, cognitive strategy use $(p=0.03$ to 0.01$)$ and self-regulation $(p=0.02$ to 0.01) than the students who were profiled as either Multiplists or Absolutists (see Table 4 for mean and standard deviation scores). The effect size, which refers to the difference between the Absolutists and Evaluativists in the MSLQ, was 1.02. The effect size, which refers to the difference between the Multiplists and Evaluativists in the MSLQ, was 0.51. Means and standard deviations by EP level according to MSLQ are shown in Table 4.

Table 4 
Our findings show that students with Evaluativist epistemic profile exhibited greater selfefficacy, intrinsic value, use of cognitive strategies and self-regulation, compared to students with either a Multiplist or an Absolutist epistemic profile. To examine further the relation between EP and learning strategies, we pursued Study 2, where students' learning strategies were assessed through individual interviews.

\section{Study 2}

In Study 2 we further examined whether individuals with different EP, who engaged in different learning strategies showed significantly different text comprehension (Research Question 2). To control the possible thread of participants' prior knowledge being a confounding factor, participants' prior knowledge was assessed and entered as a covariate in the analysis pursued in Study 2.

Sample

The sample of Study 2 included 20 students (11 girls and 9 boys, across schools), of the same sample that was used in Study 1. To compare students with different EP, the least and most mature developed EP groups were selected. Ten participants were randomly collected from the group of Absolutists, the group with the least mature developed epistemic beliefs, while another ten participants were randomly collected from the Evaluativists, which has the most mature developed epistemic beliefs.

\section{Instruments}

\section{Prior-knowledge test}

To access students' prior-knowledge a written instrument including an open-ended question about Christopher Columbus, who was the topic of the text used, was employed. The question included was: "What do you know about Christopher Columbus?". Students were asked to write all that they knew about the topic for the needs of the present study. 
The participants read two contradictory texts about Christopher Columbus, which were administered in a counterbalanced order. The first was a 175-word text which presented Columbus as an explorer of the "New World" who won the support of the Spanish monarchy to make a voyage of discovery, hoping to find a western passage to Asia (Toll, 2011). The second was a 165-word text which presented Christopher Columbus as an exploiter of the "New World" who fought and killed some native tribes (C-mann, 2011). It is worth noting that the students that read the texts did not have any difficulty in reading.

\section{Text comprehension measures}

To measure students' text comprehension, we adapted a test from Royer, Carlo, Dufrense and Mestre (1996). The test consisted of 15 statements about the Christopher Columbus' text, 8 of which were correct and 7 incorrect (see Table 5). Participants were asked to indicate which statements were correct. The statements were piloted before the study.

Table 5

\section{Procedure}

After participants completed the Prior-knowledge test, they were asked to read two texts about Christopher Columbus. The instructions that were given to the students were to read the text, taking as much time as they wished to, in order to prepare for a test that would follow. Students were asked to express their thoughts aloud. The researcher, first author, who was sitting next to the students, observed, took notes about participants' behaviour and gave reminders, when needed, for thinking aloud as the session progressed. An audio recorder was used to record the students' comments. The interviews were then transcribed and coded. At the same session, participants were asked to complete a comprehension test about the texts they had read.

\section{Coding Schemes}


Prior knowledge

Prior knowledge was assessed through one open-ended question about Christopher Columbus. One point was given for each correct knowledge statement provided by students and no points were given for each incorrect statement. The score ranged from 1 to 3 .

Learning Strategies - Think aloud protocols

Participants' protocols were transcribed, segmented, and then coded by the two authors, for identifying the learning strategies that participants employed during learning. The notes taken during the interview were also taken into consideration. Five mutually exclusive categories of learning strategies were delineated in the coding scheme: Underlining, understanding vocabulary, summarising, repeating information and quick reading (see Table 6). The Interrater reliability (Cohen's kappa) was .85. Disagreements were resolved through discussion.

Table 6

Furthermore, learning strategies were coded as effective and less effective according to the coding system developed by Harris, Moran and Moran (2011). Underlining, understanding vocabulary and summarising were coded as effective learning strategies, whereas repeating information and quick reading were coded as less effective strategies.

Text comprehension measures

Participants received a score for their text comprehension based on the number of correct answers they provided in the 15 statements that were included in the text comprehension test. In particular, participants received seven points for each correct judgment of a statement - as correct or incorrect. Participants' score could range from 0 to 105 .

\section{Results and Discussion}


In addition to examining research question 1 using data from the questions for assessing students' learning strategies, we performed a t-test between epistemic profile and learning strategies in order to study whether students with different levels of EP employ different learning strategies. The analysis showed an agreement between self-report and think aloud results since, Evaluativists engaged in more effective learning strategies than Absolutists. Evaluativists engaged more in understanding vocabulary $(M=5.00, S D=1.22$ vs $M=1.75, S D$ $=1.32, t=3.64, \mathrm{df}=19, p<.001)$ than Absolutists, in underlying $(M=6.67, S D=2.56 \mathrm{vs} M=$ 3.33, $S D=1.14, t=4.47, d f=19, p=.03)$ and in summarising, $(M=10.77, S D=2.44$ vs $M=$ 2.31, $\mathrm{SD}=1.12, t=5.79, d f=19, p=.02)$. The analysis also showed that Absolutists engaged more often in less effective learning strategies such as repeating information, $(M=2.45, S D=$ 1.87 vs $M=6.63, S D=2.59, t=3.58, d f=19, p=.01)$ and quick reading, $(M=3.54, S D=1.51$ vs $M=10.47, S D=2.55, t=4.76, d f=19, p<.001$ ) than Evaluativists (Figures 1 and 2). These findings confirmed the findings obtained through self-report measures in Study 1. Figure 1

Figure 2

For answering research question 2- that is "Do individuals with different EP, who engage in different learning strategies, exhibit significantly different text comprehension?"-we performed a two-way ANCOVA (Level of EP X Learning Strategies) on text comprehension. The score on prior knowledge test served as covariate. Results showed a two way interaction between EP and learning strategies, $F(2,11)=4.33, p=.04$. The effect of prior knowledge was not statistically significant $(p=0.30)$.

The interaction was examined further with post hoc comparisons of text comprehension (Scheffe's test, $\alpha=0.05$ ). Post hoc comparisons, revealed that the Evaluativist participants who made summary notes performed better on the text comprehension test $(M=94.55 ; S D=2.30)$ than those who either underlined the text information $(M=79.72 ; S D=5.27)$ or tried to understand the vocabulary $(M=73,22 ; S D=2.18)$. In relation to the Absolutist participants, 
those who made summary notes $(M=82.51 ; S D=4.86)$ and those who understood the vocabulary $(M=82.73 ; S D=2.90)$ performed better on text comprehension than those who tried to underline text information $(M=73.22 ; S D=1.25)$.

There was also a statistically significant main effect of EP showing that Evaluativists performed better on the text comprehension test $(M=13.07)$ than Absolutists $(M=10.8),(p=$ $.02)$. There was no main effect of learning strategies $(p=0.16)$, however.

Our findings show that students with Evaluativist epistemic profiles engaged in more effective learning strategies, such as underlining and summarizing when reading a history text, compared to students with Absolutist epistemic profiles. In other words, students who viewed research and interpretation of data as the means of knowing used more effective learning strategies than students who believed that knowledge is absolute and certain.

\section{Conclusions}

The present study informs our understanding about the relationship between learning strategies and EP in adolescents and whether individuals with different EP, who engage in different learning strategies exhibit significantly different text comprehension in the domain of history, highlighting thus the important role of EP for learning. In general, our findings show that a mature epistemic perspective is associated with effective usage of learning strategies and text comprehension.

Our findings show that students who viewed research and interpretation of data as the means of knowing used more effective learning strategies than students who believed that knowledge is absolute and certain. The finding of a relation between learning strategies and Evaluativist EP offers support to theoretical views supporting that EP is related to cognitive processing and learning (Muis, 2007, Kuhn, 2001, Bråten and Strømsø, 2005; Iordanou, 2016a). Results from several other studies (Barzilai \& Zohar, 2012; Muis, 2008; Muis \& Franco, 2009, 2010; Stahl, Pieschl, \& Bromme, 2006; Iordanou, Muis, \& Kendeou, 2018) also reveal that, 
typically, students who adopt more constructivist EP use more deep processing learning strategies, such as elaboration (e.g., paraphrasing, summarizing, creating analogies) and critical thinking (applying previous knowledge to new situations, evaluation of information) compared to students who adopt less constructivist EP (e.g., knowledge is simple, certain, and unquestionably justified by authority figures such as teachers and passively constructed).

The positive relation between EP, learning strategies and text comprehension found in the present work suggests that EP and learning strategies play an important role in text comprehension. Students with mature EP achieved a deep understanding during reading the history text. In contrast, students who believed that knowledge is certain merely memorized information from the text and they did not achieve a deep understanding. Our findings are in line with the findings of Bråten and Strømsø (2011), who found that people who believed that knowledge is simple, understood texts as comprising of individual parts of information.

The present study adds to the literature by showing that one's EP is related to the learning strategies that one employs in the context of studying history and to one's comprehension of history texts. Different strategies such as testing, processing and organizational strategies have been found to promote active engagement in learning and lead to higher performance levels (Anderman, Patrick, Hruda, \& Linnenbrink, 2002). Furthermore, the present findings that highlight the role of EP in learning (Muis, 2007) have important educational implications suggesting that we need to invest and support the development of students' EP through intervention programmes (Iordanou, 2016a; Brownlee, Purdie, \& Boulton-Lewis, 2001; Ferguson \& Bråten, 2013). Intervention programmes based on argumentation activities appear promising for the development of students' EP (Alexander, 2016; Iordanou, 2016b; Iordanou \& Constantinou, 2014; 2015; Barzilai \& Chinn, 2017; Greene, 2016). It is important for the students to become active participants and to acquire control of their learning process if they 
are to become life-long learners and critical thinkers in important subjects of study such as that of history. 


\section{References}

Alexander, P. A. (2016). The arguments for and the reasoning about epistemic cognition. In Handbook of epistemic cognition (pp. 112-122). Routledge.

Anderman, L. H., Patrick, H., Hruda, L. Z., \& Linnenbrink, E. A. (2002). Observing classroom goal structures to clarify and expand goal theory. Goals, goal structures, and patterns of adaptive learning, 243-278.

Barzilai, S., \& Chinn, C. A. (2017). On the goals of epistemic education: Promoting apt epistemic performance. Journal of the Learning Sciences, 1-37.

Barzilai, S., \& Zohar, A. (2012). Epistemic thinking in action: Evaluating and integrating online sources. Cognition and Instruction, 30(1), 39-85.

Baxter-Magolda, M. (2008). The evolution of self-authorship. In M. S. Khine (Ed.), Knowing, knowledge and beliefs: Epistemological studies across diverse cultures (pp. 45-64). Dordrecht, The Netherlands: Springer.

Bråten, I., \& Britt, M.A., Strømsø, H.I., \& Rouet, J.-F. (2011). The role of epistemic beliefs in the comprehension of multiple expository texts: Towards an integrated model. Educational Psychologist, 46, 48-70.

Bråten, I., Strømsø, H. I. (2005). The relationship between epistemic cognition, implicit theories of intelligence, and self-regulated learning among Norwegian postsecondary students. British Journal of Educational Psychology, 75, 539-65.

Braten, I., \& Stromso, H. I. (2006). Epistemological beliefs, interest, and gender as predictors of internet-based learning activities. Computers in Human Behavior, 22, 1027-1042.

Bråten, I., Strømsø, H. I., \& Samuelstuen, M. S. (2007). Dimensions of topic-specific epistemic cognition as predictors of multiple text understanding. Learning and Instruction, 18, 513527.

Bråten, I., \& Strømsø, H. I. (2011). Measuring strategic processing when students read multiple texts. Metacognition and Learning, 6(2), 111-130. 
Bråten, I., Strømsø, H. I., \& Samuelstuen M. S. (2008). Are sophisticated students always better? The role of topic-specific personal epistemology in the understanding of multiple expository texts. Contemporary Educational Psychology, 33, 814-840.

Brownlee, J., Purdie, N., \& Boulton-Lewis, G. (2001). Changing epistemological beliefs in preservice teacher education students. Teaching in Higher Education 6(2), 247-268.

Chinn, C. A., Rinehart, R. W., \& Buckland, L. A. (2014). Epistemic cognition and evaluating information: Applying the AIR model of epistemic cognition. Processing inaccurate information: Theoretical and applied perspectives from cognitive science and the educational sciences, 425-453.

C-mann, C. (2011). Seeds, Germs and Slaves. Published at The New York Times.

Conley, A., Pintrich, P., Vekiri, I., \& Harrison, D. (2004). Changes in epistemological beliefs in elementary science students. Contemporary Educational Psychology, 29, 186-204.

Dillon, S. (2011, June 14). U.S. Students Remain Poor at History, Tests Show. The New

York Times. Retrieved from https://www.nytimes.com /2011/06/15/ education/15history.html

Duckworth, A. L., \& Kern, M. L. (2011). A meta-analysis of the convergent validity of selfcontrol measures. Journal of Research in Personality, 45(3), 259-268.

Ferguson, L. E., \& Bråten, I. (2013). Student profiles of knowledge and epistemic beliefs: Changes and relations to multiple-text comprehension. Learning and Instruction, 25, 4961.

Garrett-Ingram, C. (1997). Something to believe in: The relationship between epistemological beliefs and study strategies. In Paper presented at the annual meeting of the American Educational Research Association, Chicago.

Graesser, A. C., Singer, M., \& Trabasso, T. (1994). Constructing inferences during narrative text comprehension. Psychological Review, 101, 371. 
Greene, J. A. (2016). Interacting epistemic systems within and beyond the classroom. Handbook of Epistemic Cognition, 265-277.

Greene, J. A., Robertson, J., \& Costa, L. C. (2011). Assessing self-regulated learning using think-aloud methods. Handbook of Self-Regulation of Learning and Performance, 313328.

Greene, J. A., Sandoval, W. A., \& Bråten, I. (Eds.). (2016). Handbook of Epistemic Cognition. Routledge.

Greene, J., Yu, S.B., \& Copeland D. Z. (2014). Measuring critical components of digital literacy and their relationships with learning. Computers \& Education, 76 (2014), 55-69.

Griffiths, M. (2002). Study skills and dyslexia in the secondary school: A practical approach. London: David Fulton.

Harris, P, R., Moran, R., \& Moran, S. (2011). Managing Cultural Differences. New York: Routledge.

Hewson, P. (2007). A case study of conceptual change in special relativity: The influence of prior knowledge in learning. European Journal of Science Education, 4, 61-78.

Hofer, B. (2000). Dimensionality and disciplinary differences in personal epistemology. Contemporary Educational Psychology, 2, 378-405.

Hofer, B. (2004). Epistemological understanding as a metacognitive process: Thinking aloud during online searching. Educational Psychologist, 39(1), 43-55.

Hofer, B. K., \& Pintrich, P. R. (1997). The development of epistemological theories: Beliefs about knowledge and knowing and their relation to learning. Review of Educational Research, 67, 88-140.

Hofer, B. K., \& Pintrich, P. R. (Eds.) (2002), Personal Epistemology: The Psychology of Beliefs About Knowledge and Knowing. Mahwah, NJ: Lawrence Erlbaum Associates.

Iordanou, K. (2016a). From theory of mind to epistemic cognition. A Lifespan perspective. Frontline Learning Research, 4(5), 106 - 119. 
Iordanou, K. (2016b). Developing epistemological understanding through argumentation in scientific and social domains. Zeitschrift für Pädagogische Psychologie. 30(2-3), 109119.

Iordanou, K., \& Constantinou, C. P. (2014). Developing pre-service teachers' evidence-based argumentation skills on socio-scientific issues. Learning and Instruction, 34, 42-57.

Iordanou, K., \& Constantinou, C. (2015). Supporting Use of Evidence in Argumentation through Practice in Argumentation and Reflection in the Context of SOCRATES Learning Environment. Science Education, 99(2), 292-311.

Iordanou, K., Kendeou., P., \& Beker, K. (2016). Argumentative Reasoning. In W. Sandoval, J. Greene, \& I., Bråten. (Eds). Handbook of Epistemic Cognition. New York, NY: Routledge.

Iordanou, K., Muis, K. R., \& Kendeou, P. (2018). Epistemic Perspective and Online Epistemic Processing of Evidence: Developmental and Domain Differences. The Journal of Experimental Education, 1-21.

Kang, M. J., Hsu, M., Krajbich, I. M., Loewenstein, G., McClure, S. M., Wang, J. T., et al. (2009). The wick in the candle of learning: Epistemic curiosity activates reward circuitry and enhances memory. Psychological Science, 20, 963-973.

Khine, M. S. (Ed.) (2008). Knowing, knowledge and Beliefs: Epistemological Studies across Diverse Cultures. Dordrecht, The Netherlands: Springer.

King, P. M., \& Kitchener, K. S. (2002). The Reflective Judgment Model: Twenty years of research on epistemic cognition. In B. K. Hofer \& P. R. Pintrich (Eds.), Personal Epistemology: The Psychology of Beliefs About Knowledge and Knowing (pp. 37-61). Mahwah, NJ: Lawrence Erlbaum Associates.

Kuhn, D. (1991). The Skills of Argument. Cambridge, England: Cambridge University Press.

Kuhn, D. (2001). How do people know?. Psychological Science, 12(1), 1-8.

Kuhn, D., Cheney, R., \& Weinstock, M. (2000). The development of epistemic cognition. Cognitive Development 15, 309-328. 
Kuhn, D., Iordanou, K., Pease, M., \& Wirkala, C. (2008). Beyond control of variables: What needs to develop to achieve skilled scientific thinking?. Cognitive Development, 23(4), 435-451.

Kuhn, D., \& Weinstock, M. (2002). What is epistemological thinking and why does it matter? In B. K. Hofer \& P. R. Pintrich (Eds.), Personal Epistemology: The Psychology of Beliefs About Knowledge and Knowing (pp. 121-144). Mahwah, NJ: Lawrence Erlbaum Associates.

Maggioni, L. (2010). Studying Epistemic Cognition in the History Classroom: Cases of Teaching and Learning to Think Historically (Doctoral dissertation).

Maggioni, L., Alexander, P. A., \& VanSledright, B. (2004). At a crossroads? The development of epistemological beliefs and historical thinking. European Journal of School Psychology, 2(1-2), 169-197

Muis, K. R. (2007). The role of epistemic beliefs in self-regulated learning. Educational Psychologist. 42(3), 173-190.

Muis, K. R. (2008). Epistemic profiles and self-regulated learning: Examining the relations in the context of mathematics problem solving. Contemporary Educational Psychology, 33, 177-208.

Muis, K. R., \& Duffy, M. C. (2013). Epistemic climate and epistemic change: Instruction designed to change students' beliefs and learning strategies and improve achievement. Journal of Educational Psychology, 105(1), 213.

Muis, K. R., \& Franco, G. M. (2009). Epistemic Beliefs: Setting the Standards for SelfRegulated Learning. Contemporary Educational Psychology, 34, 4, 306-318.

Perry, W. G. (1970). Forms of Intellectual and Ethical Development in The College Years: A Scheme. New York: Holt, Rinehart, and Winston.

Piaget, J. (1950). The Psychology of Intelligence. London: Routledge \& Kegan Paul.

Pintrich P.R., \& De Groot Elisabeth V. (1990). Motivation \& self-regulated learning components of classroom academic performance. Journal of Educational Psychology, 82, 1. 
Pintrich, P.R., Wolters, C., \& Baxter, G. (2000). Assessing metacognition and self-regulated learning. In G. Schraw \& J. Impara (Eds.), Issues in the Measurement of Metacognition (pp. 43-97). Lincoln, NE: Buros Institute of Mental Measurements.

Ryan, M. P. (1984a). Conceptions of prose coherence: Individual differences in epistemological standards. Journal of Educational Psychology, 76(6), 1226-1238.

Ryan, M. P. (1984b). Monitoring text comprehension: Individual differences in epistemological standards. Journal of Educational Psychology, 76(2), 249-258.

Schommer, M. (1990). Effects of beliefs about the nature of knowledge on comprehension. Journal of Educational Psychology, 82, 498-504.

Schommer, M. (1994b). Synthesizing epistemological belief research: Tentative understandings and provocative confusions. Educational Psychology Review, 6(4), 293- 319.

Schommer-Aikins, M. (2002). An evolving theoretical framework for an epistemological belief system. In B. Hofer \& P. Pintrich (Eds.), Personal Epistemology: The Psychology of Belief About Knowledge and Knowing, (pp. 103-118). Hillsdale, NJ: Lawrence Erlbaum.

Schommer-Aikins, M., \& Easter, M. (2006). Ways of knowing and epistemic cognition: combined effect on academic performance. Educational Psychology, 26, 411-423.

Significance of history for the educated citizen. (2018). Retrieved from https://phi.history.ucla.edu/nchs/preface/significance-history-educated-citizen/

Stahl, E., Pieschl, S., \& Bromme, R. (2006). Task complexity, epistemological beliefs and metacognitive calibration: An exploratory study. Journal of Educational Computing Research, 35, 319-338.

Toll, I. (2011). The Less Than Heroic Christopher Columbus, Published at: The New York Times.

Topcu, M. S., \& Yılmaz-Tüzün, O. (2008) Relationships among preservice science teachers' epistemological beliefs, epistemological world views, and self-efficacy beliefs International Journal of Science Education, 30(1), 65-85. 
VanSledrigh, B., Burkholdt, S., \& Montgomery, S. (2018). Exploring Change in Epistemic Beliefs Among History Teachers. Social Studies Education Review, 7, 1-24. 